\title{
Preliminary Study on the Relationship Between LncRNA GAPLINC Expression and Clinical Pathology of Esophageal Squamous Cell Carcinoma and Its Metastasis Mechanism
}

\section{Peng Wang}

Nantong University Fifth Affiliated Hospital: Jiangsu Taizhou People's Hospital

\section{Song Yang}

Nantong University Fifth Affiliated Hospital: Jiangsu Taizhou People's Hospital

\section{Shengbin Dai}

Nantong University Fifth Affiliated Hospital: Jiangsu Taizhou People's Hospital

\section{Qingtao Ni}

Nantong University Fifth Affiliated Hospital: Jiangsu Taizhou People's Hospital

Huilan Liu

Nantong University Fifth Affiliated Hospital: Jiangsu Taizhou People's Hospital Lei Yu

Nantong University Fifth Affiliated Hospital: Jiangsu Taizhou People's Hospital

Kaijin Lu

Nantong University Fifth Affiliated Hospital: Jiangsu Taizhou People's Hospital

\section{Gaohua Han}

Nantong University Fifth Affiliated Hospital: Jiangsu Taizhou People's Hospital Junxing Huang ( $\nabla$ huangjunxing_a@163.com )

Nantong University Fifth Affiliated Hospital: Jiangsu Taizhou People's Hospital

\section{Research}

Keywords: Esophageal squamous cell carcinoma, long non-coding RNA, GAPLINC, biomarker

Posted Date: September 24th, 2020

DOI: https://doi.org/10.21203/rs.3.rs-73561/v1

License: (c) (1) This work is licensed under a Creative Commons Attribution 4.0 International License. Read Full License 


\section{Abstract}

\section{Background}

Long non-coding RNA (IncRNA) GAPLINC (gastric adenocarcinoma predictive long intergenic noncoding RNA) plays a carcinogenic role in a variety of different tumor types. It is deserved to explore the biological function of LncRNA GAPLINC in the development of esophageal cancer.

\section{Methods}

Tissues of 40 patients undergoing esophageal squamous cell carcinoma (ESCC) radical surgery were collected, including ESCC tissues and corresponding adjacent normal tissues. Quantitative real-time PCR (qRT-PCR) was used to detect the expression of LncRNA GAPLINC and evaluate the relationship between its expression and ESCC clinicopathology. The expression level of LncRNA GAPLINC in human ESCC cell line (TE11) was detected by qRT-PCR. After specific siRNA interference, the expression of LncRNA GAPLINC was detected. The effects of LnCRNA GAPLINC on ESCC cell proliferation, migration and invasion were detected by flow cytometry, cell counting kit-8 (cck-8) and Transwell, respectively.

Results

1. The expression level of LncRNA GAPLINC in ESCC tissues was significantly higher than that in the corresponding adjacent normal tissues $(P<0.05)$. 2. The high expression of LncRNA GAPLINC in ESCC was correlated with the degree of tumor differentiation of patients $(P<0.05)$, but not age, gender, smoking and alcohol history, tumor location, tumor size and invasion depth $(P>0.05)$. 3. Compared with human esophageal normal epithelial cell lines, the expression of LncRNA GAPLINC was significantly increased in human ESCC cell line $(P<0.05)$. 4. Cck-8 experiment showed that LncRNA GAPLINC overexpression increased the growth rate of cells $(P<0.05)$. Transwell experiment showed that LncRNA GAPLINC overexpression increased the ability of cell migration and invasion compared $(P<0.05)$. Annexin $V$ assay showed that LncRNA GAPLINC silencing made apoptosis increase at the early stage $(P<0.05)$.

\section{Conclusions}

1. LncRNA GAPLINC was highly expressed in ESCC tissues and human ESCC cell line. LncRNA GAPLINC expression level was significantly correlated with tumor differentiation degree in ESCC. Our results suggested that LncRNA GAPLINC may be used as a biomarker for the diagnosis and monitoring of ESCC. 2. Downregulation of LnCRNA GAPLINC in human ESCC cell line could inhibit the proliferation, migration and invasion of tumor cells. Our study revealed that LncRNA GAPLINC may play a role as an oncogene in ESCC and be a potential therapeutic target.

\section{Background}

esophageal squamous cell carcinoma (ESCC) has become one of the six most common malignant tumors in the world, with about 572,000 new cases and 509,000 deaths in 2018, ranking 7th and 6th 
among all tumors in the world, respectively ${ }^{1}$. China has the highest incidence and mortality rate of ESCC in the world, accounting for $70 \%{ }^{2}$. It should be noted that more than $95 \%$ of patients with ESCC diagnosed for the first time are in advanced stage, with a poor prognosis and a 5-year survival rate of only about $30 \%^{3}$, . The current researches cannot completely explain the pathogenesis of ESCC ${ }^{5}$. There are many factors related to the occurrence and development of ESCC 6 . Therefore, it is of great significance for the prevention and treatment of ESCC to further study its pathogenesis, clarify its biological behavior, identify its susceptible genes and specific biomarkers.

LncRNA is a kind of long non coding RNA with more than 200 nucleotides in length, which is mainly transcribed by RNA Poymerase II and widely distributed in the human genome. The current studies have discovered a huge quantity of LncRNAs widespread existing in each kind of malignant tumor. These LncRNAs could regulate the expression of oncogenes and tumor suppressor genes in different ways and play an important role in the occurrence, development, metastasis and recurrence of tumors ${ }^{8}$. Another side, the LncRNAs are stable in circulating body fluids such as plasma and urine, providing a new basis for the diagnosis and treatment of malignant tumors. Therefore, searching new LncRNAs as diagnostic biomarkers and therapeutic targets for malignant tumors will become a research hotspot.

The GAPLINC is $924 \mathrm{bp}$ in length, located on the short arm of human chromosome 18 , and the RNA length after transcription is $643 \mathrm{nt}^{9}$. LncRNA GAPLINC is first confirmed to be significantly increased in gastric cancer tissues, and its high expression could reduce cancer cell apoptosis, promote proliferation and invasion ability. Its expression level is positively correlated with tumor volume, distant metastasis, lymph nodes proportion and clinical grade. The expression level of GAPLINC is strongly correlated with CD44 and its role as a proto-oncogene is partly depended partly on CD44 ${ }^{10}$. In the study of colon cancer, GAPLINC is also observed to play the role of oncogene. At present, there are few researches reporting on LncRNA GAPLINC. It is deserved to explore the biological function of LncRNA GAPLINC in the development of ESCC.

\section{Materials And Methods}

\section{Materials}

\section{Patients and tumor tissue}

In this study, 40 pairs of specimens were collected, including ESCC cancer tissues and normal esophageal tissues. These tissue were from the patients under thoracic surgery in 2018. Basic information and clinicopathological data of ESCC patients were collected. The normal tissue adjacent to the cancer required $\geq 5 \mathrm{~cm}$ from the edge of the tumor tissue.

\section{Clinical and pathological data:}

Of the 40 patients with esophageal squamous cell carcinoma in this study, 34 were male (85\%) and 6 were female (15\%); 31 were over 60 years old (77.5\%) and less than 60 years old 9 patients (22.5\%); 13 
patients with lymph node metastasis (32.5\%), 27 patients without lymph node metastasis $(67.5 \%) ; 11$ patients with T1 to T2 (27.5\%), 29 patients with T3 to T4 (accounting for 72.5\%) (Table 1).

Table 1 Clinicopathological data of $\mathbf{4 0}$ patients with ESCC

\begin{tabular}{|c|c|c|}
\hline Clinical information & No. & $\%$ \\
\hline \multicolumn{3}{|l|}{ Gender } \\
\hline Male & 34 & 85 \\
\hline Female & 6 & 15 \\
\hline \multicolumn{3}{|l|}{ Age } \\
\hline$\nabla 60$ & 31 & 77.5 \\
\hline$\leq 60$ & 9 & 22.5 \\
\hline \multicolumn{3}{|l|}{ Tumor location } \\
\hline High in chest & 0 & \\
\hline Middle in chest & 14 & 35 \\
\hline Low in chest & 26 & 65 \\
\hline \multicolumn{3}{|l|}{ Tumor size } \\
\hline$\triangle 4 \mathrm{~cm}$ & 22 & 55 \\
\hline$\leq 4 \mathrm{~cm}$ & 18 & 45 \\
\hline \multicolumn{3}{|l|}{ Differentiation } \\
\hline High & 4 & 10 \\
\hline Middle & 19 & 47.5 \\
\hline Low & 17 & 42.5 \\
\hline \multicolumn{3}{|l|}{ Infiltration } \\
\hline Mucosa and submucosa & 5 & 12.5 \\
\hline Superficial muscularis & 6 & 15 \\
\hline Deep muscularis & 11 & 27.5 \\
\hline All & 18 & 45 \\
\hline \multicolumn{3}{|l|}{ Lymph node metastasis } \\
\hline Yes & 13 & 32.5 \\
\hline No & 27 & 67.5 \\
\hline
\end{tabular}


Cell lines:

The human ESCC cell lines (KYSE-150, KYSE-450, KYSE510, TE-10, TE-11) were purchased from Shanghai Meixuan Biotechnology Co., Ltd. The human-derived normal esophageal epithelial cell line (HetIA) was purchased from Shanghai Meixuan Biotechnology Co., Ltd. All cell lines were preserved and cultured in our central laboratory.

2. Reagents

Primers:

\begin{tabular}{|lll|}
\hline Name & Forward & Reverse \\
\hline hGAPLINC & CCACATCCAGGGGCTATCAA & CACAATCAGGGCTCTTGGACT \\
hGAPDH & GCACCGTCAAGGCTGAGAAC & TGGTGAAGACGCCAGTGGA \\
\hline
\end{tabular}

Reagents:

\begin{tabular}{|lll|}
\hline Name & Company & CAT. \\
\hline RNA extraction kit & $\begin{array}{l}\text { Shanghai Meixuan Biological } \\
\text { Technology Co., Ltd. }\end{array}$ & MX0015 \\
\hline RT reagent Kit & Takara Co., Ltd. & RR047A \\
\hline SYBR Premix Ex Taq & $\begin{array}{l}\text { Shanghai Meixuan Biological } \\
\text { Technology Co., Ltd. }\end{array}$ & MX200017 \\
\hline Nuclease-free water & Ambion Co., Ltd. & \#AM99386 \\
\hline Ethanol & $\begin{array}{l}\text { Sinopharm Group Chemical Reagent } \\
\text { Co., Ltd. }\end{array}$ & AR10009218 \\
\hline Chloroform & $\begin{array}{l}\text { Sinopharm Group Chemical Reagent } \\
\text { Co., Ltd. }\end{array}$ & $2006-06-08$ \\
\hline $\begin{array}{l}\text { CCK-8 cell proliferation and cytotoxicity } \\
\text { detection kit }\end{array}$ & Biyuntian Co., Ltd. & C0037 \\
\hline $\begin{array}{l}\text { Fetal bovine serum } \\
\begin{array}{l}\text { Annexin V-Alexa Fluor647/PI Apoptosis } \\
\text { Detection Kit }\end{array}\end{array}$ & Solarbio Co., Ltd. & Sh30084.03 \\
\hline
\end{tabular}

\section{Methods}

1. Q-PCR

Sample preparation: 
Tissue samples: After taking out fresh samples, freeze them with liquid nitrogen as soon as possible and store at -80 degrees

Cell sample: Digest the cells using a cell scraper or trypsin, and then centrifuge at $12000 \mathrm{rpm} / \mathrm{min}$ for 5 minutes. Collect the cells and store at -80 degrees.

Other samples: Save the samples as soon as possible - 80 degrees.

\section{Total RNA extraction:}

After cutting the tissue sample into small pieces, liquid nitrogen is ground (50mg) into a powder and transfer to a $1.5 \mathrm{ml}$ tube without RNase (cell samples and other liquid samples do not need to be ground, skip to the next step directly).

$700 \mathrm{ul}$ of lysate per tube, $200 \mathrm{ul}$ of sample to be extracted/ground sample, vortex for 10 s until completely mix. Add 20ul proteinase K solution and 20ul magnetic beads to obtain purified RNA. Short-term storage at -20 degrees, long-term storage at -80 degrees.

Reverse transcription of RNA into CDNA:

Genomic DNA removal reaction: Prepare the reaction solution for removing genomic DNA according to the ingredients in Table 2 on ice. The reaction mixture (Master Mix) should be prepared according to the number of reactions +2 , and then transfer into reaction tubes. Finally, RNA samples are added to perform various reactions.

\section{Table 2 Reaction soulution}

\begin{tabular}{|ll|}
\hline 5×gDNA Eraser Buffer & $2.0 \mu \mathrm{l}$ \\
\hline Total RNA & $1 \mu \mathrm{g}$ \\
\hline gDNA Eraser & $1.0 \mu \mathrm{l}$ \\
\hline RNase Free dH2O & up to $10 \mu \mathrm{l}$ \\
\hline
\end{tabular}

Reverse transcription reaction: Prepare the reverse transcription reaction solution according to the ingredients in Table 3 on ice. First prepare the reaction mixture (Master Mix) according to the reaction number +2 , and then dispense $10 \mu$ into the reaction tube to ensure the accuracy of the solution preparation. Perform a reverse transcription reaction immediately after gently mixing.

\section{Table 3 Reaction solution}




\begin{tabular}{|ll|}
\hline Genomic DNA removal reaction solution & $10.0 \mu \mathrm{l}$ \\
\hline PrimeScript RT Enzyme Mix I & $1.0 \mu \mathrm{l}$ \\
\hline RNase Free dH2O & $4.0 \mu \mathrm{l}$ \\
\hline $5 \times$ PrimeScript Buffer 2 & $4.0 \mu \mathrm{l}$ \\
\hline RT Primer Mix & $1.0 \mu \mathrm{l}$ \\
\hline Total & $20 \mu \mathrm{l}$ \\
\hline
\end{tabular}

qRT-PCR:

Prepare PCR reaction solution on ice according to the ingredients in Table 4. After preparing the solution, perform Real Time PCR reaction immediately. After the test, confirm the Real Time PCR amplification curve and melting curve, and calculate the $2-\Delta \Delta$ ct value.

\section{Table 4 PCR Soulution}

\begin{tabular}{|c|c|}
\hline 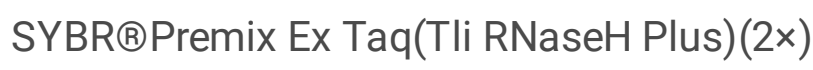 & $10.0 \mu \mathrm{l}$ \\
\hline ROX Reference Dye(50x) & $0.4 \mu \mathrm{l}$ \\
\hline PCR Reverse Primer $(10 \mu \mathrm{M})$ & $0.4 \mu \mathrm{l}$ \\
\hline PCR Forward Primer(10 $\mu \mathrm{M})$ & $0.4 \mu \mathrm{l}$ \\
\hline DNA & $2.0 \mu \mathrm{l}$ \\
\hline $\mathrm{dH} 2 \mathrm{O}$ & $6.8 \mu \mathrm{l}$ \\
\hline Total & $20.0 \mu \mathrm{l}$ \\
\hline
\end{tabular}

\section{Cell culture}

The cells are cultured by complete medium (containing 90\% DMEM high glucose $+10 \%$ fetal bovine serum) under sterile conditions, placed in a $37^{\circ} \mathrm{CO}_{2}$ incubator.

\section{Cell infection:}

When the healing degree of the transfected cells reaches $80 \%$, the lentivirus can infect the cells, and the complete culture medium does not contain double antibodies. Lentivirus was added to the cell culture fluid according to different $\mathrm{MOI}$ values in the preliminary experiment. After $8 \mathrm{~h}$, change the fresh culture medium and continue cultivating for $24 \mathrm{~h}$.

3. CCK-8 assay 
Collect cells in different groups, adjust the cells to $106 \mathrm{cells} / \mathrm{ml}$, and add $100 \mu \mathrm{l}$ of cell suspension to the 96-well plate. Adjust the incubator to $37^{\circ} \mathrm{C}, 5 \% \mathrm{CO} 2$ conditions, and then put into the culture plate, incubate for $72 \mathrm{~h}$. Add $10 \mu \mathrm{l} \mathrm{CCK}-8$ solution to each well and continue to incubate the plate in the incubator for 1-4 hours. The absorbance at $450 \mathrm{~nm}$ was measured with a microplate reader.

\section{Transwell assay}

Resuspend cells in basal medium and count, adjust the number of cells to $5^{\star} 105$ power $/ \mathrm{ml}$. According to different groups, inoculate $5 * 104$ cells in the transwell chamber, add $500 \mu$ l of fresh medium containing $20 \%$ FBS in the lower chamber, gently shake the cells to distribute them evenly, and incubate at 37 degrees $5 \% \mathrm{CO} 2$ for $12 \mathrm{~h}$. Take out the transwell chamber, carefully wipe off the cells that have not passed through the chamber with a cotton swab, and fix it with $4 \%$ paraformaldehyde for 10 minutes. Dye with crystal violet dyeing solution for 5 minutes, and wash until the basement membrane is transparent. Observe, photograph, count and analyze under the microscope.

\section{Apoptosis assay}

\section{Cell preparation!}

The cell suspension is prepared by digesting the cultured cells with trypsin. Take out $10 \mu \mathrm{l}$ of cell suspension for cell counting, and then dilute with complete medium to a concentration of 100,000 cells $/ \mathrm{ml}$. Cell suspension was added to the 6 -well culture plate with a volume of $2 \mathrm{ml}$ per well. When the cell growth reached $70 \%$ confluence, the cell culture fluid was discarded and the cells were collected after 16 hours of culture.

\section{Annexin V-Alexa Fluor647 cell apoptosis[}

Move the cell culture fluid into a suitable centrifuge tube, wash the adherent cells once with PBS, and digest the cells with an appropriate amount of trypsin cell digest solution (which may contain EDTA). Incubate at room temperature. When the adherent cells are gently blown down, remove the pancreatin cell digest. It is necessary to avoid excessive digestion of pancreatin during the process. Add the cell culture fluid collected in step 2A and mix well. Transfer to $1000 \mathrm{~g}$ in a centrifuge tube and centrifuge for 5 minutes, then discard the supernatant. After collecting the cells, resuspend the cells gently with PBS and count. Take 50,000-100,000 resuspended cells, centrifuge at $1000 \mathrm{~g}$ for 5 minutes, discard the supernatant and add $195 \mu$ I Annexin V-FITC binding solution to resuspend the cells gently. Add $5 \mu$ l Annexin V-Alexa Fluor647 and mix gently. Add 10 $\mu$ l propidium iodide staining solution and mix gently. Incubate at room temperature $\left(20-25^{\circ} \mathrm{C}\right)$ in the dark for $10-20$ minutes, then place in an ice bath. Immediately perform flow cytometry.

\section{Results}

1. qRT-PCR Assay 
The expression levels of LnCRNA GAPLINC in ESCC tissues, paracancerous tissues and five human esophageal squamous carcinoma cell lines were detected by qRT-PCR technology. After qRT-PCR amplification, the single-peak dissolution curves were obtained and the CT value was between 25 and 35 cycles, indicating that the amplification effect was reliable, no pollution, and no primer dimer formation.

\subsection{Expression of LncRNA GAPLINC in ESCC tissues and adjacent tissues}

Real-time fluorescence quantitative PCR was used to detect the expression of LncRNA GAPLINC, a longnon-coding RNA in 40 pairs of ESCC tissues and corresponding adjacent tissues. The relative expression of LncRNA GAPLINC in normal tissues was $1.669 \pm 0.028$, and the expression of tumor tissues was 1.748 \pm 0.026 . LncRNA GAPLINC expression in ESCC tissue was significantly higher than normal tissues adjacent to cancer (Figure 2 ) and the difference was statistically significant ( $\left.{ }^{*} p<0.05\right)$.

1.2 Relationship between abnormal expression of LncRNA GAPLINC in esophageal squamous cell carcinoma and its clinicopathology

Based on the clinical and pathological data of 40 patients, we further analyzed the relationship between LncRNA GAPLINC expression and clinical factors (gender, age, history of tobacco and alcohol, tumor location, length of esophageal lesion, depth of invasion, degree of differentiation, lymph node metastasis, etc). The analysis of statistical results showed that the relative expression of LncRNA GAPLINC was significantly related to the degree of differentiation $(P<0.05)$, and was not related to the patient's gender, age, history of tobacco and alcohol, tumor location, esophageal lesion length, infiltration depth, and lymph node metastasis (Table 5).

\section{Table 5 Relationship between LncRNA GAPLINC and clinical characteristics of ESCC patients}




\begin{tabular}{|c|c|c|c|}
\hline Clinical information & No. & $\%$ & $P$ value \\
\hline Gender & & & $P=0.428$ \\
\hline Male & 34 & 85 & \\
\hline Female & 6 & 15 & \\
\hline Age & & & $P=0.269$ \\
\hline$\nabla 60$ & 31 & 77.5 & \\
\hline$\leq 60$ & 9 & 22.5 & \\
\hline Smoking & & & $P=0.152$ \\
\hline Yes & 16 & 40 & \\
\hline No & 24 & 60 & \\
\hline Drinking & & & $P=0.791$ \\
\hline Yes & 15 & 37.5 & \\
\hline No & 25 & 62.5 & \\
\hline Tumor location & & & VS Low in chest \\
\hline High in chest & 5 & 12.5 & $P=0.648$ \\
\hline Middle in chest & 14 & 35 & $P=0.444$ \\
\hline Lower middle in chest & 10 & 25 & $P=0.764$ \\
\hline Low in chest & 10 & 25 & \\
\hline Unknown & 1 & 2.5 & \\
\hline Tumor size & & & $P=0.629$ \\
\hline$\otimes 4 \mathrm{~cm}$ & 20 & 50 & \\
\hline$\leq 4 \mathrm{~cm}$ & 20 & 50 & \\
\hline Differentiation & & & VS High \\
\hline High & 4 & 10 & \\
\hline Higher middle & 6 & 15 & $P=0.015$ \\
\hline Middle & 13 & 32.5 & $P=0.011$ \\
\hline Lower middle & 8 & 20 & $P=0.017$ \\
\hline Low & 9 & 22.5 & $P=0.022$ \\
\hline Infiltration & & & VS All \\
\hline
\end{tabular}




\begin{tabular}{|lccc|} 
Mucosa and submucosa & 5 & 12.5 & $P=0.700$ \\
\hline Superficial muscularis & 2 & 5 & $P=0.979$ \\
Deep muscularis & 5 & 12.5 & $P=0.538$ \\
\hline All & 28 & 70 & \\
Lymph node metastasis & & & \\
\hline Yes & 15 & 35.5 & $P=0.114$ \\
No & 25 & 62.5 & \\
\hline
\end{tabular}

Chi-square test $\mathrm{P}<0.05$

2. Effect of LncRNA GAPLINC on TE11 cell behavior

Real-time fluorescence quantitative PCR was used to detect the expression of LncRNA GAPLINC in five human ESCC cell lines (KYSE-150, KYSE-450, KYSE510, TE-10, TE-11) and human normal esophageal epithelial cell lines (Hte-1A). The expression of LncRNA GAPLINC in esophageal squamous carcinoma cell lines was significantly higher than that of human normal epithelial esophageal cell lines $(P<0.05)$ (Figure 3). According to the expression level, we selected the TE-11 cell line with the highest expression level for the subsequent experiments. The expression of LncRNA GAPLINC in human ESCC cell lines was consistent with its expression in esophageal tumor tissues, confirming that GAPLINC played an important role in the development of esophageal cancer.

The IncGAPLINC interference sequence and overexpression sequence were designed according to the software. Synthesized and connected to the vector. And then amplified and sequenced.

Vector plasmid:

pLV-EGFP(2A)Puro-IncGAPLINC;

pLV-shRNA-EGFP(2A)puro-IncGAPLINC-RNAi 


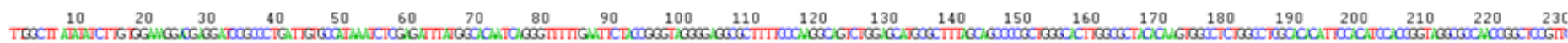

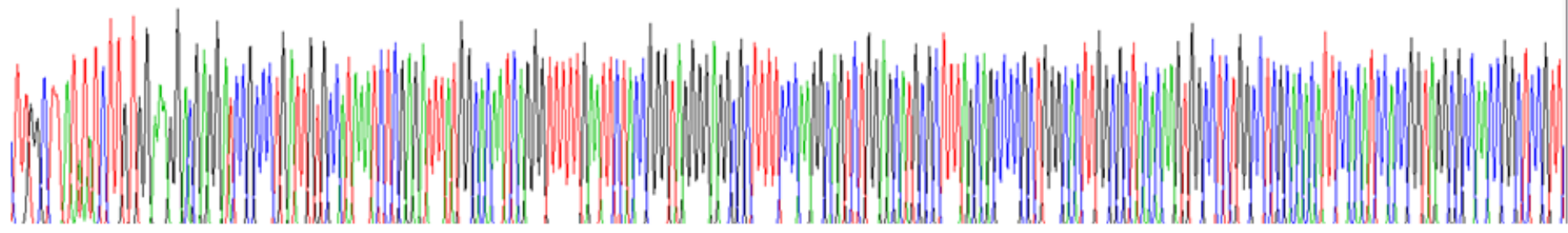

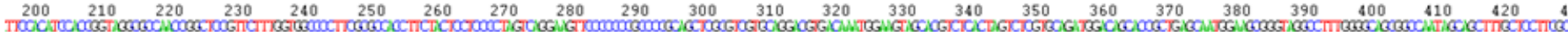

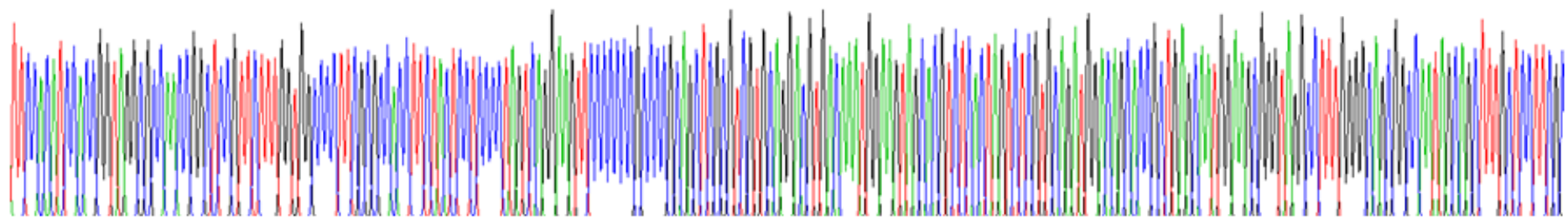

\section{LncGAPLINC-Knockdown}
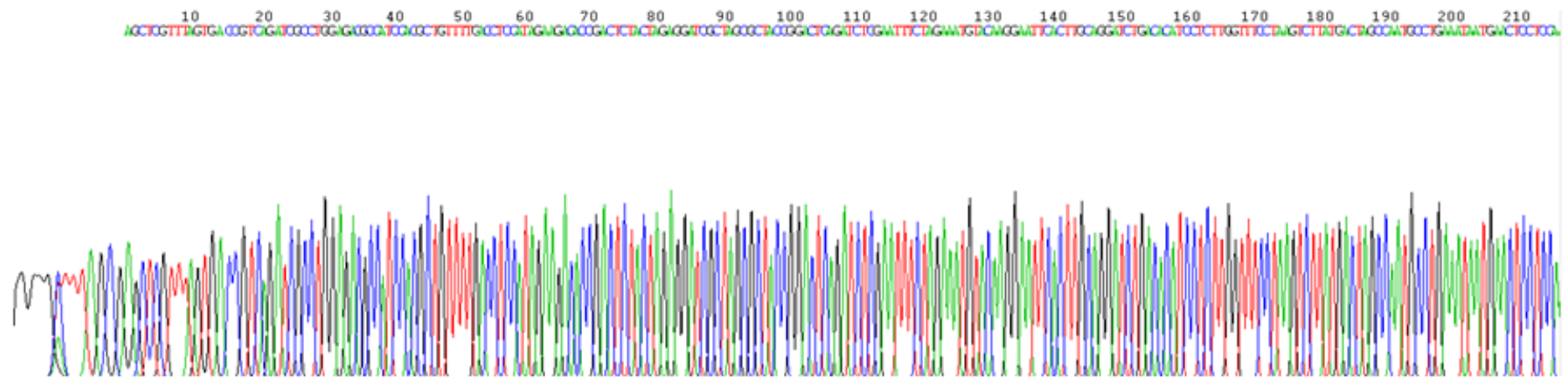

Page $12 / 25$ 


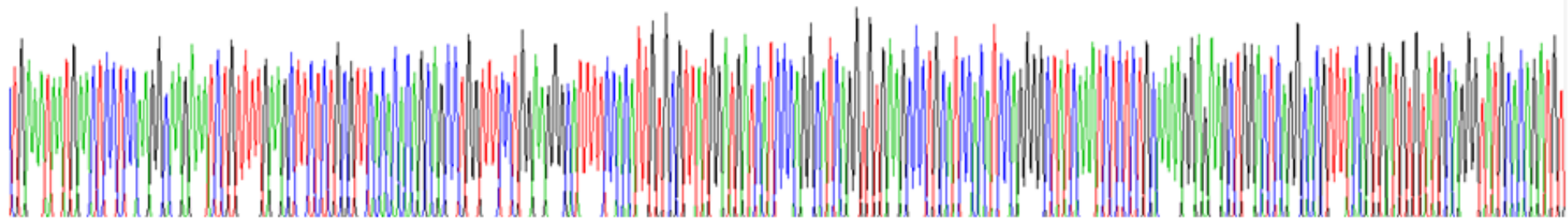

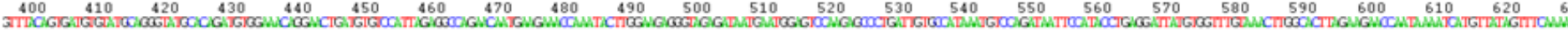

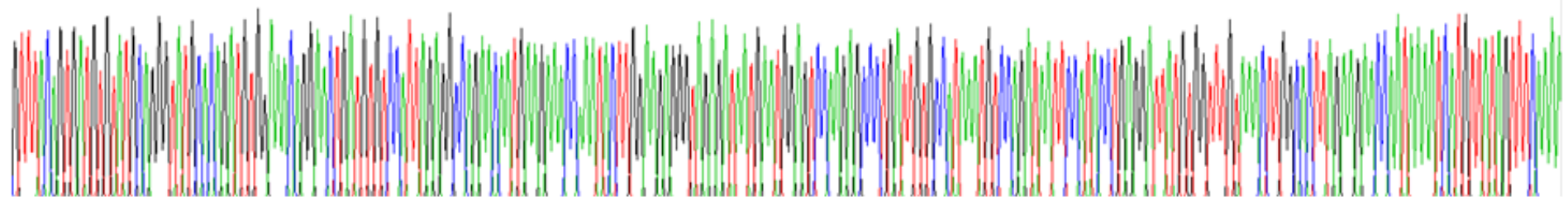

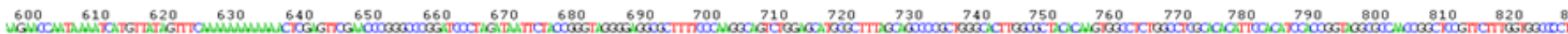

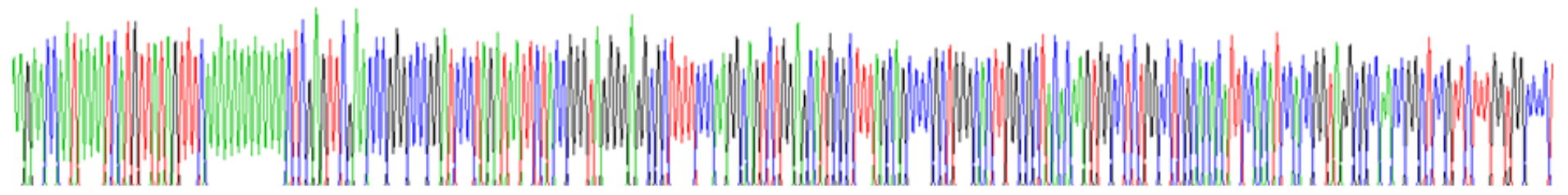

\section{LncGAPLINC-Overexpression}

The lentivirus was prepared, and then TE-11 cells were infected for subsequent experiments.

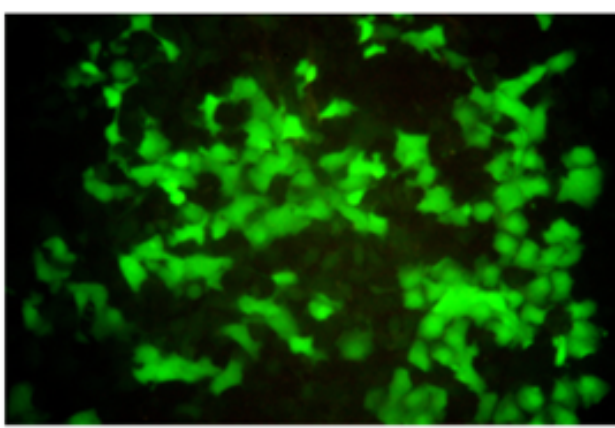

沉默组慢病击侵染 $72 \mathrm{~h}$ 后絧㴔荧光照片

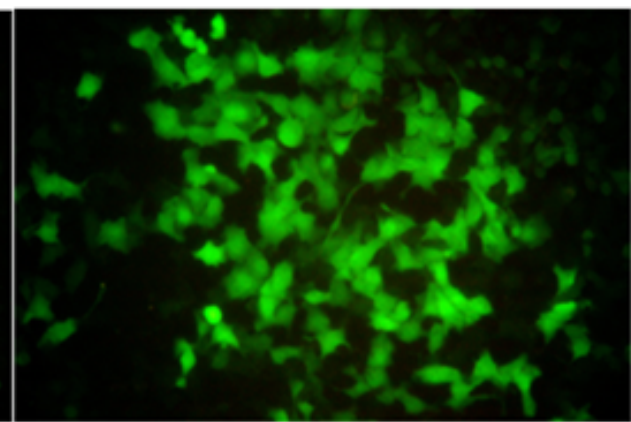

过表达组慢病毒侵染 $72 \mathrm{~h}$ 后细胞荧光祭片

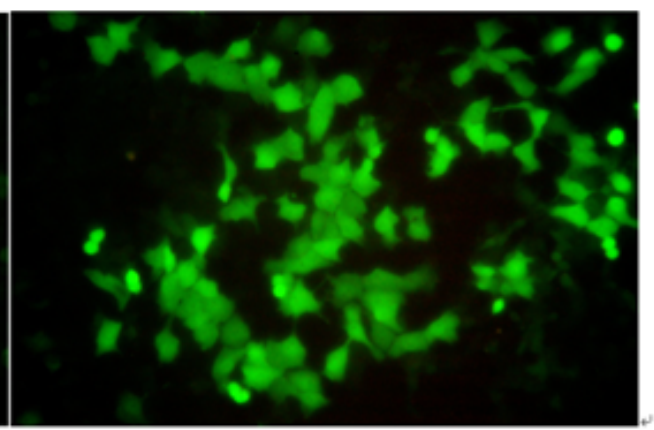

阴性对影病毒侵染細胞 $72 \mathrm{~h}$ 后藀光照片

2.1 Knockdown and overexpression of LncRNA GAPLINC could affect cell proliferation 
The cellular viabillity of TE11 cell line after LncGAPLINC-Knockdown and LncGAPLINC-Overexpression were shown in Figure 4. We found that LncGAPLINC-Knockdown decreased the cell proliferation rate, and LnGAPLINC-Overexpression increased the cell proliferation rate $(P<0.05)$.

2.2 Knockdown and overexpression of LncRNA GAPLINC could affect cell migration and invasion

Transwell cell migration and invasion experiment was used to detect TE11 cell migration and invasion ability after LncGAPLINC-Knockdown and LncGAPLINC-Overexpression. Compared with the control group, the number of migration and invasion decreased after knocking down and increased after overexpressing $(P<0.05)$ (Figure 5 and Figure 6).

2.3 Knockdown and overexpression of LncRNA GAPLINC could affect cell apoptosis

The cell apoptosis was detected in LncGAPLINC-Knockdown cell line, LncGAPLINC-Overexpression cell line and control cell line. Compared with the control group, knocking down LncRNA GAPLINC lead to an increase in cell apoptosis (the rate, $35.97 \pm 3.58 \%, \mathrm{P}<0.05$ ) (Figure 7 ). However, there was no significant changes between the LncGAPLINC-Overexpression cell line and the control cell line (Table 6).

\section{Table 6 Apoptosis rate of LncGAPLINC-Knockdown cell line, LncGAPLINC-Overexpression cell line.}

\begin{tabular}{|llll|}
\hline & control & silence & overexpression \\
\hline Apoptosis rate $(\%)$ & $0.49 \pm 0.045$ & $35.97 \pm 3.58$ & $0.70 \pm 0.083$ \\
\hline
\end{tabular}

2.4 The RNA level in LncGAPLINC-Knockdown cell line, LncGAPLINC-Overexpression cell line

The RNA level of LncRNA GAPLINC in three different cell lines was shown in Figure 8. The knockdown and overexpression of LncRNA GAPLINC in these cell line were significant $(P<0.05)$.

\section{Discussion}

Esophageal cancer is one of the most common malignant tumors. It has ranked sixth among the causes of tumor-related mortality worldwide, and the morbidity has ranked seventh ${ }^{11}$. The regional differences in esophageal cancer incidence are obvious. The northern France, Africa, Central Asia and Central and South America are the high incidence areas. In China, the high incidence areas include Taihang Mountain, Northern Jiangsu Area, Dabie Mountain, Southern Fujian, Chaoshan of Guangdong, and Eastern Qinling Mountains $^{12}$. The main tissue types of esophageal cancer are esophageal adenocarcinoma (EAC) and ESCC. ESCC is the most common tissue type of esophageal cancer and the main pathological type in China. $80 \%$ of patients with ESCC in the world come from Central Asia and Southeast Asia, and ESCC in China accounts for half of them. Recent studies have confirmed that multidisciplinary comprehensive treatment is the main research direction of ESCC treatment. Although the diagnosis and treatment methods of ESCC are continuously optimized and new drugs are continuously developed, ESCC has the characteristics of high invasiveness, treatment resistance and easy metastasis. Therefore, the overall 5- 
year survival rate is not obvious. At present, the clinical prognosis of ESCC mainly depends on the TNM staging. But the prognosis of patients is very different in the same TNM stage. It is not comprehensive enough to rely on the clinical pathological staging to evaluate the prognosis. The inherent molecular biological mechanism is also worth exploring.

Long-chain-non-coding RNA is long as more than 200 nucleotides and does not encode protein. According to the position, LncRNAs can be divided into 5 types: sense LncRNA, antisense LncRNA, bidirectional LncRNA, intron LncRNA and intergenic LncRNA ${ }^{13}$. Although LncRNAs cannot encode proteins, they can directly interact with DNA, RNA and proteins in order to regulate variety of mechanisms ${ }^{14}$.

In the recent years, studies have found that genetic abnormalities are one of the main causes of ESCC, indicating that ESCC occurrence might be related to environmental factors and genetic factors. In order to achieve the accurate early diagnosis of ESCC and the better prognosis evaluation, we need to further explore its pathogenesis at the genomic level. Previous studies have confirmed that the genesis and development of esophageal cancer involved many genes, such as C-MYC, EGFR, INT-2 and P53. The research on LncRNA in esophageal cancer is not rare, but it is still one of the hot spots in current tumor research. Compared with miRNA, LncRNA is much more abundant at function and mechanism and it may be the core factors in RNA regulation. More and more studies have shown that LncRNA is differentially expressed in tumors ${ }^{15}$. Several studies have shown that LncRNA has a relatively stable secondary structure in body fluids, which can be detected in plasma or other body fluids ${ }^{16}$. LncRNA can predict the occurrence or prognosis of various malignant tumors. And LncRNA may become a new class of tumor markers and potential therapeutic targets ${ }^{17}$. Although many studies have shown that LncRNA is closely related to the metastasis and progression of ESCC, the relationship between LncRNA and the metastasis is poorly understood. Therefore, identifying LncRNAs expression in ESCC and exploring their role in ESCC metastasis may further expand our understanding of ESCC metastasis and open up a new situation for the prevention and treatment of esophageal cancer.

LncRNA GAPLINC is first confirmed to highly express in gastric cancer tissues. Both RT-qPCR and ISH assay have confirmed that GAPLINC expression in gastric cancer tissues is significantly higher than corresponding normal gastric mucosal tissues, indicating GAPLINC may be a major risk factor for poor prognosis. GAPLINC is an important predictor of patient prognosis analysis, which is independent of AJCC stage. Its high expression can reduce the apoptosis of cancer cells and promote the proliferation and invasion ability. The expression level is positively correlated with tumor volume, distant metastasis, tumor involvement, lymph nodes proportion and clinical grade. Studies have shown that the p53 mutants will lost the function of wildtype p53s and obtain the function of different oncogenes. The p53 mutant R248W can combine with the GAPLINC promoter sequence to promote its expression. There is a strong correlation between GAPLINC expression level and CD44. The proto-oncogene function of GAPLINC partly depends on $C D 44^{10}$. Similar results have been observed in colon cancer study. These researches have indicated that LncRNA GAPLINC could act as an oncogene in gastric and colon cancer. The function and 
mechanism of LncRNA GAPLINC in esophageal squamous cell carcinoma is unknown. This study collected 40 cases of ESCC tissues and normal tissues adjacent to cancer. The results of qRT-PCR assay showed that LncRNA GAPLINC had a significant high expression in ESCC. Combining with clinical pathological data analysis, we found that LnCRNA GAPLINC expression was no related to the patient's age, sex, history of tobacco and alcohol, tumor location, esophageal lesion length, depth of invasion, lymph nodes metastasis but closely related to tumor differentiation degree. The study revealed the correlation between LncRNA expression level and tumor differentiation degree, indicating the potential of LnCRNA GAPLINC as a biomarker for diagnosis in ESCC. In order to further explore the function of LncRNA GAPLINC in esophageal tumors, we used qRT-PCR technology to detect five human esophageal squamous carcinoma cell lines (KYSE-450, KYSE-510, KYSE-150, TE-10 and TE-11). Compared with the normal esophageal epithelial cell line (HET-1A), LncRNA GAPLINC expression was up-regulated in these five esophageal squamous carcinoma cell lines, which was similar to the ESCC tissue. We selected TE-11 cell lines to knock down and overexpress LncRNA GAPLINC. The apoptosis was detected by flow cytometry assay and the proliferation ability by CCK-8 test. At the same time, the migration and invasion of cancer cell was also detected. The Annexin $V$ apoptosis test had shown that knocking down of GAPLINC lead to a significant difference of apoptosis. But overexpression of GAPLINC had no effect on apoptosis. Knocking down LncRNA GAPLINC lead to a decrease on cell proliferation, migration and invasion. Another side, overexpressing LncRNA GAPLINC led to an increase on cell proliferation, migration and invasion. It was confirmed that downregulation of LncRNA GAPLINC could significantly inhibit the proliferation, migration and invasion ability of ESCC cells in vitro. We believed that LncRNA GAPLINC played a role as an oncogene in the occurrence and development of ESCC, and may become a potential treatment for ESCC biological target.

In summary, we found that the expression of LnCRNA GAPLINC was upregulated in ESCC, which was obviously related to tumor differentiation degree. It was consistent with the role of LncRNA GAPLINC in other cancer types. However, this study still had the following deficiencies: 1 . The tissue collected by a single center was lacking in the extensiveness of the sample; 2 . The number of samples was too small and it was necessary to further expand the number of tests; 3 . The advanced patients samples were lack and the clinical and pathological analysis was not comprehensive; 4 . The collection of samples was rushed, and the patient survival data was lack.

Studies have confirmed that the occurrence and development of esophageal cancer cannot owe to a factor or a factor that can be determined, but the result of a combination of internal and external factors such as environment, genes, and genetics. With more and more studies, we have achieved some results about LncRNA function in tumor. But most researches are limited to the point-to-point relationship between a single tumor and a single LncRNA. And the potential mechanism cannot be fully elucidated. Genes cross each other, dominate each other, and regulate each other. Downregulation or upregulation of one gene may affect the entire gene network. A single regulation mode cannot fully explain the occurrence and development of tumors. We can understand the entire biological process of tumorigenesis and development by systematic research. Exploring the LncRNA is to find possible highefficiency tumor biomarkers or gene therapy targets, and open a new situation for the prevention and 
treatment of tumors. There is no doubt that LncRNA will provide broad prospects and rich resources for tumor research. But it is still in the laboratory research stage and cannot be widely used in clinical practice. It requires the continuous efforts and perseverance of researchers to expand the depth and breadth of research in order to solve the current problems and create a new situation in cancer prevention.

\section{Conclusion}

We explored the function of LnCRNA GAPLINC in ESCC tissues and human-derived ESCC cell line (TE11), and the relationship between LnCRNA GAPLINC expression and clinical pathology of ESCC patients. The LncRNA GAPLINC showed significantly high expression in ESCC and five human ESCC cell lines. And the high expression level was significantly positively correlated with the degree of differentiation of ESCC tumor cells, suggesting LncRNA GAPLINC abnormal expression may be used as a biomarker for diagnosis and monitoring of ESCC. In human ESCC cell line (TE11), using siRNA silencing and overexpression strategies, downregulating LncRNA GAPLINC expression can inhibit the proliferation, migration and invasion ability of ESCC cancer cells. Our results revealed that LncRNA GAPLINC could acts as a carcinogen in the occurrence and development of ESCC and it may be an effective biomarker for ESCC diagnosis and a potential therapeutic target.

\section{Abbreviations}

\begin{tabular}{ll} 
cck-8 & cell counting kit-8 \\
\hline EAC & esophageal adenocarcinoma \\
\hline ESCC & esophageal squamous cell carcinoma \\
\hline GAPLINC & gastric adenocarcinoma predictive long intergenic noncoding RNA \\
\hline IncRNA & Long non-coding RNA \\
\hline qRT-PCR & Quantitative real-time PCR
\end{tabular}

\section{Declarations}

\section{Ethics approval and consent to participate}

Human samples experimented in this study were performed referring to the Helsinki Declaration and approved by the ethical committee of Jiangsu Taizhou People's Hospital.

\section{Consent for publication}

All authors agree to submit the article for publication.

\section{Availability of data and materials}


All date generated or analyzed during this study were all included in this present article.

\section{Competing interests}

The authors declare that the research was conducted in the absence of any commercial or financial relationships

\section{Funding}

Not Applicable

\section{Authors' Contributions}

$\mathrm{GH}$ and $\mathrm{JH}$ designed this study, wrote and revised the manuscript. PW and SY mainly performed the experiment. SD, QN, HL, LY and KL were involved in providing guidance on experimental techniques. All authors have read and approved the final manuscript.

\section{Acknowledgments}

Not applicable.

\section{References}

[1] Freddie B , Jacques F , Isabelle S , et al. Global Cancer Statistics 2018: GLOBOCAN Estimates of Incidence and Mortality Worldwide for 36 Cancers in 185 Countries[J]. CA: A Cancer Journal for Clinicians, 2018.

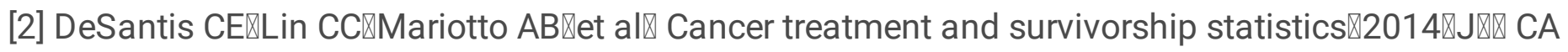
Cancer J Clin $₫ 2014 \llbracket 64$ ( 4) : 252邓271》

[3] Minashi K, Nihei K, Mizusawa J, et al. Efficacy of Endoscopic Resection and Selective Chemoradiotherapy for Stage I Esophageal Squamous Cell Carcinoma. Gastroenterology. 2019;157(2):382-390.

[4] Changing cancer survival in China during 2003-15: a pooled analysis of 17 population-based cancer registries[J]. The Lancet Global Health, 2018, 6(5):e555-e567.

[5] Enzinger PC,Mayer RJ.Esophageal Cancer.N Engl J Med,2003,349(23):2241-2252

[6] Matejcic M , Parker M I . Gene-environment interactions in esophageal cancer[J]. CRC Critical Reviews in Clinical Laboratory Sciences, 2015, 52(5):21.

[7] Carl E , Morton C C . Identification and function of long non-coding RNA[J]. Frontiers in Cellular Neuroscience, 2013, 7. 
[8] Camacho C V , Choudhari R , Gadad S S . Long Noncoding RNAs and Cancer, an Overview[J]. Steroids, 2018, 133:1-12.

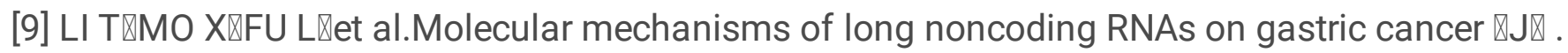
Oncotarget $₫ 2016 \rrbracket 7 \rrbracket 8 \otimes \square 8601-8612$.

[10]HU Y $₫ W A N G ~ J 囚 Q I A N ~ J 囚 e t$ al.LongnoncodingRNA GAPLINC regulates CD44-dependent cell

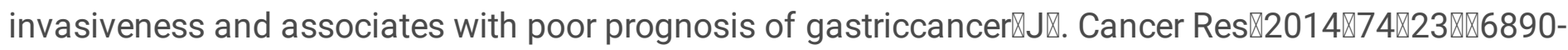
6902.

[11]Freddie B , Jacques F , Isabelle S , et al. Global Cancer Statistics 2018: GLOBOCAN Estimates of Incidence and Mortality Worldwide for 36 Cancers in 185 Countries[J]. CA: A Cancer Journal for Clinicians, 2018.

[12]Ferlay J, Shin H R., Bray F, Forman D, Mathers C, Parkin D.M, Estimates of worldwide burden of cancer in 2008: GLOBOCAN 2008, International journal of cancer, 127 (2010) 2893-2917.

[13]Huang $J \mathrm{~L}$, Zheng $L$, Hu $Y \mathrm{~W}$, et al. Characteristics of long non-coding RNA and its relation to hepatocellular carcinoma[J]. Carcinogenesis, 2014, 35(3):507-514.

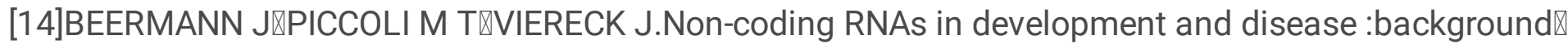

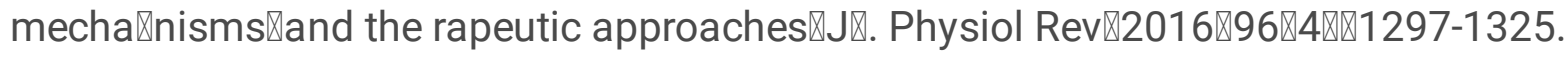

[15]Huang W, Huang F, Lei Z, Luo H. LncRNA SNHG11 Promotes Proliferation, Migration, Apoptosis, and Autophagy by Regulating hsa-miR-184/AGO2 in HCC. Onco Targets Ther. 2020;13:413-421.

[16]Mitra S A, Mitra A P, Triche T J. A Central Role for Long Non-Coding RNA in Cancer[J]. Frontiers in Genetics, 2011, 3:17.

[17]Reis E M , Sergio V A . Perspectives of Long Non-Coding RNAs in Cancer Diagnostics[J]. Frontiers in Genetics, 2012, 3.

\section{Figures}



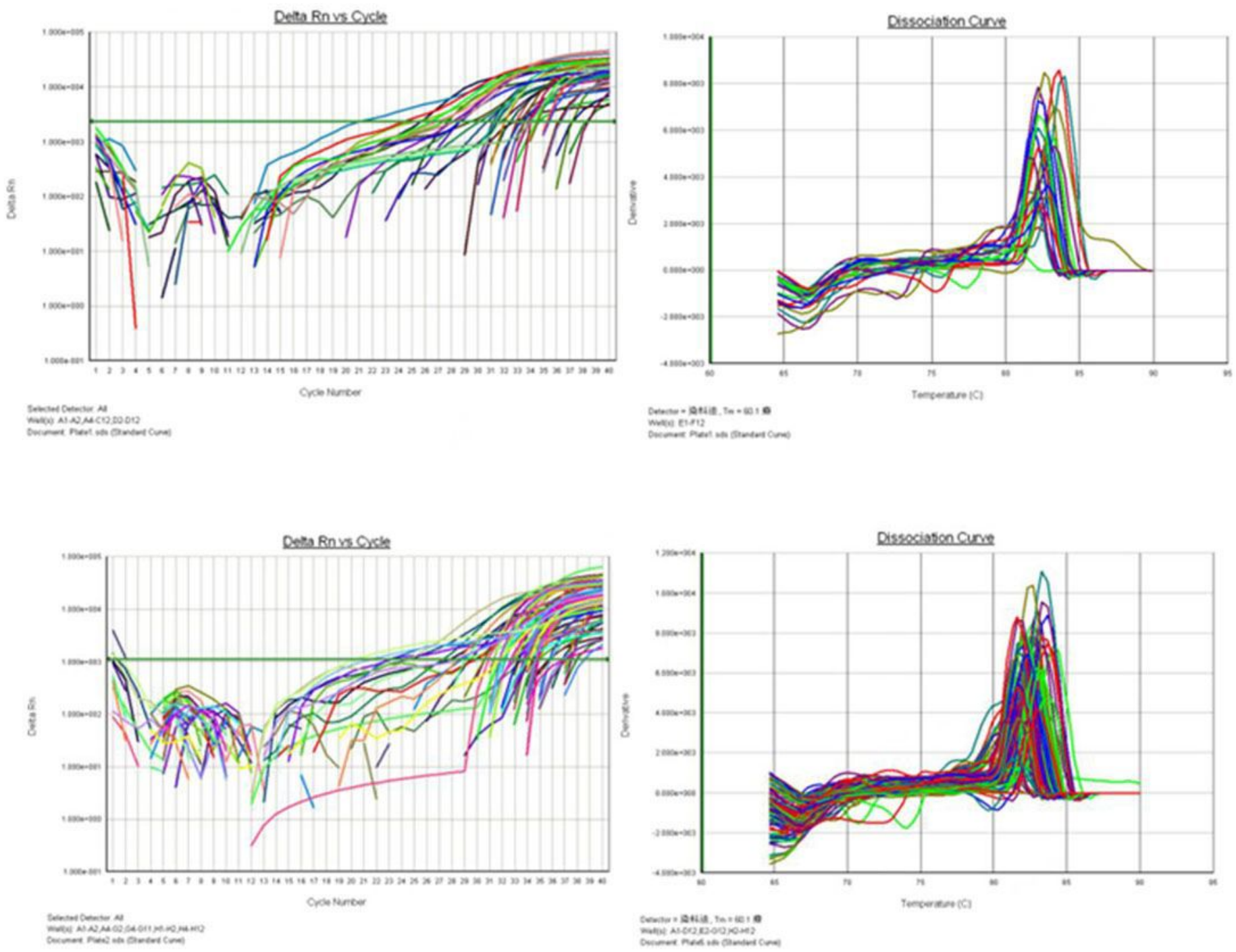

Figure 1

PCR amplification curve and dissolution curve. 


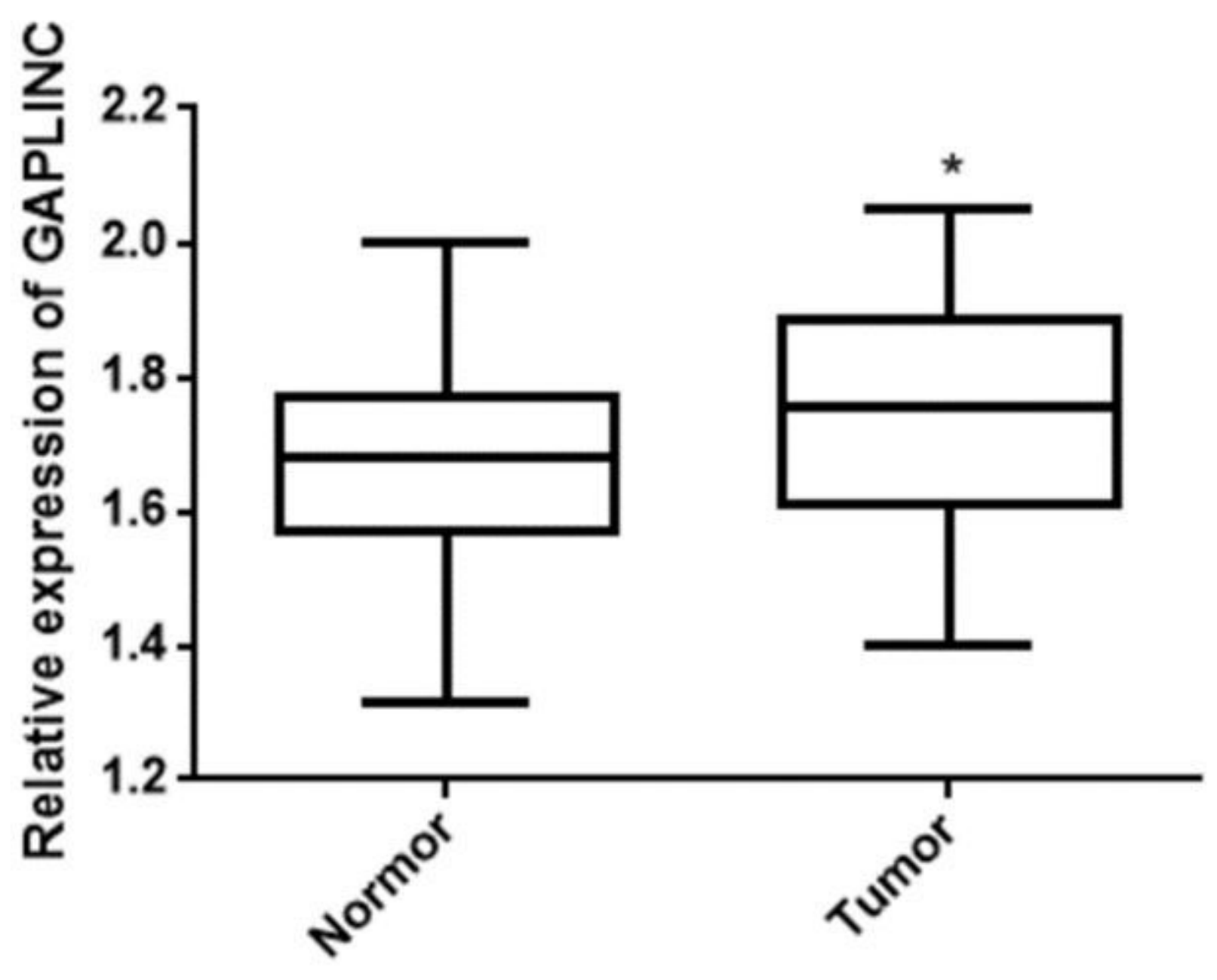

Figure 2

LncRNA GAPLINC expression levels in ESCC tissues and adjacent normal esophagus tissues $\left({ }^{*} \mathrm{p}<0.05\right)$. 


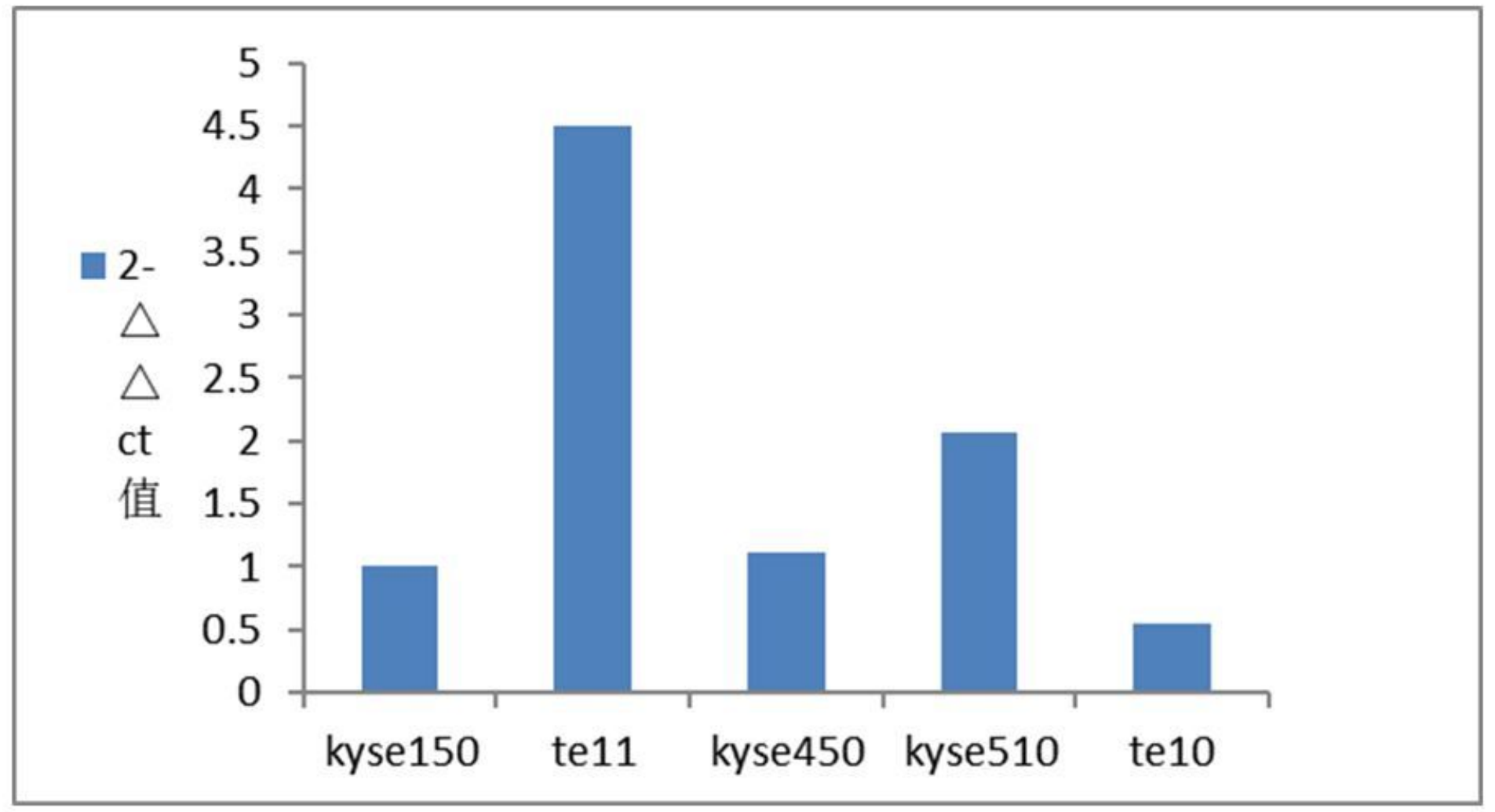

Figure 3

LncRNA GAPLINC expression in five human ESCC cell lines 


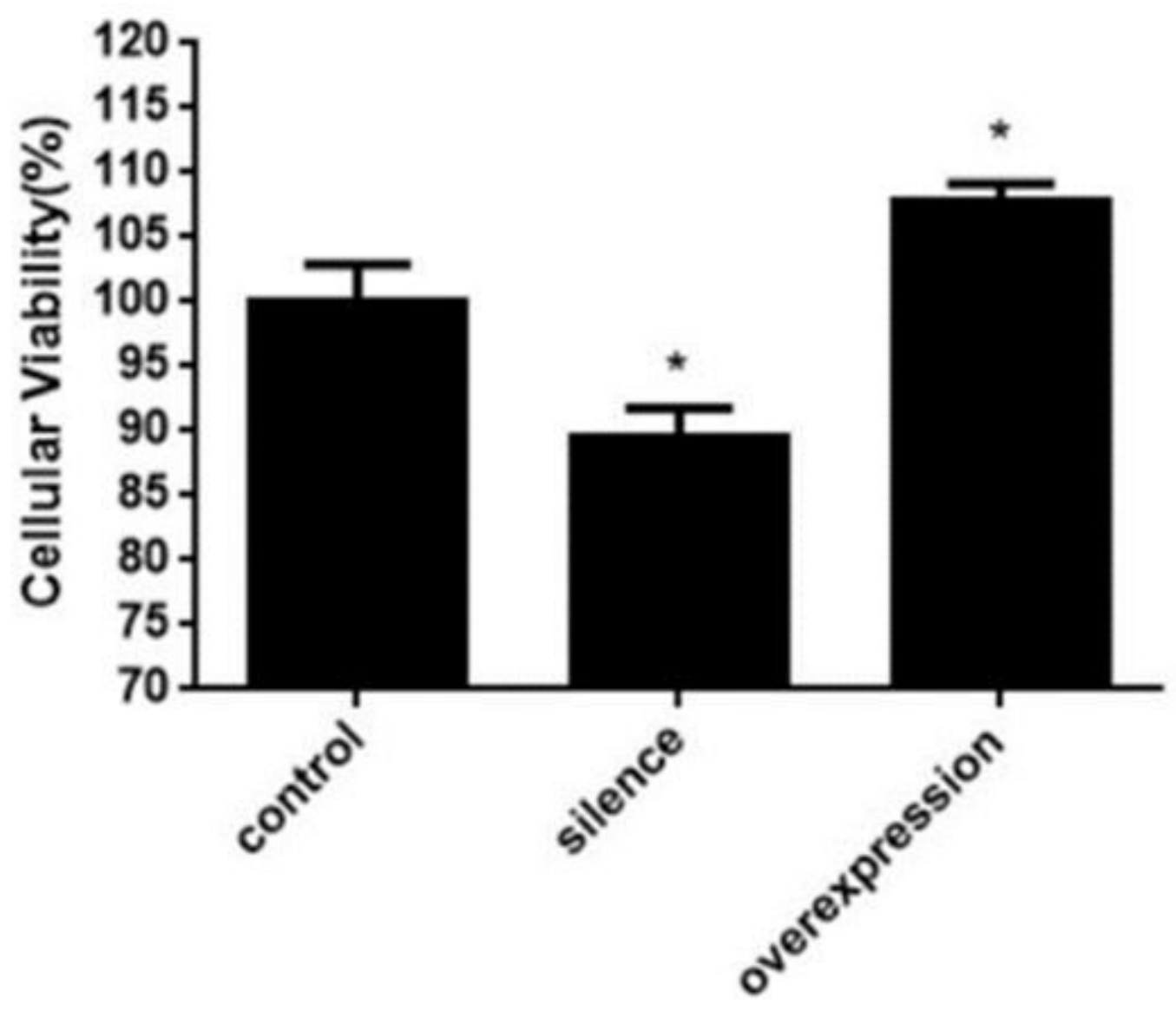

Figure 4

The cell proliferation of LncGAPLINC-Knockdown cell line, LncGAPLINC-Overexpression cell line $\left({ }^{*} \mathrm{p}<0.05\right)$.
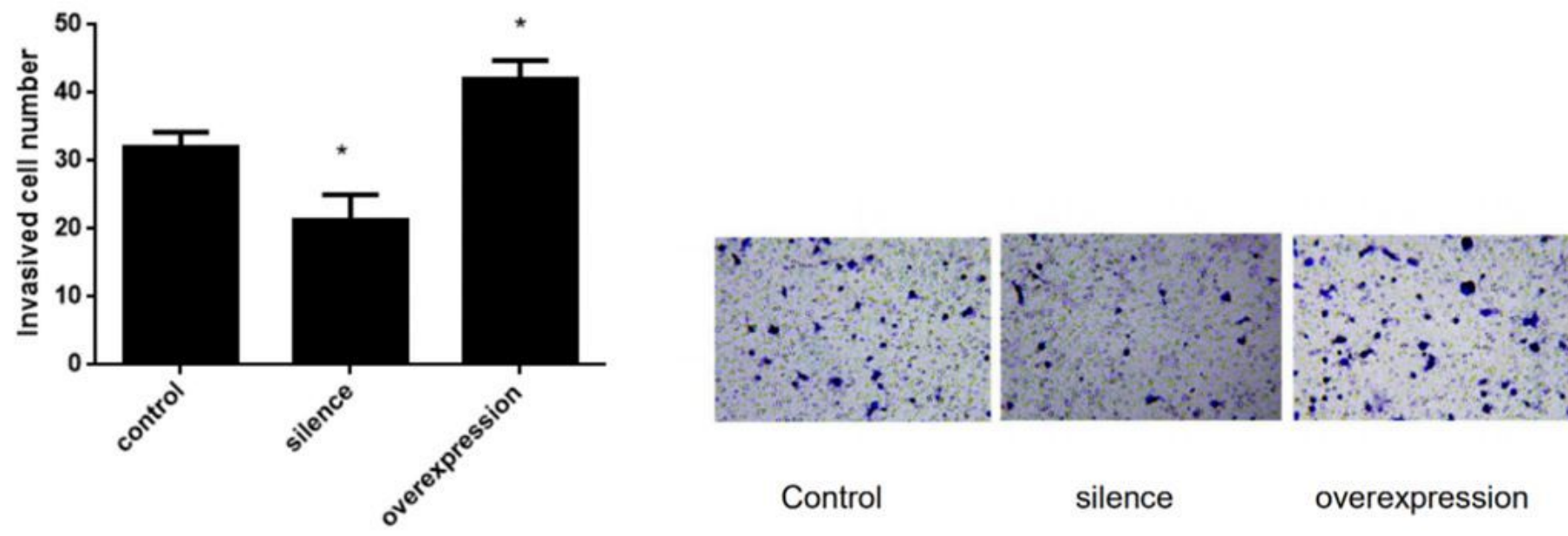

Figure 5 
The cell migration of LncGAPLINC-Knockdown cell line, LncGAPLINC-Overexpression cell line $\left({ }^{*} p<0.05\right)$.

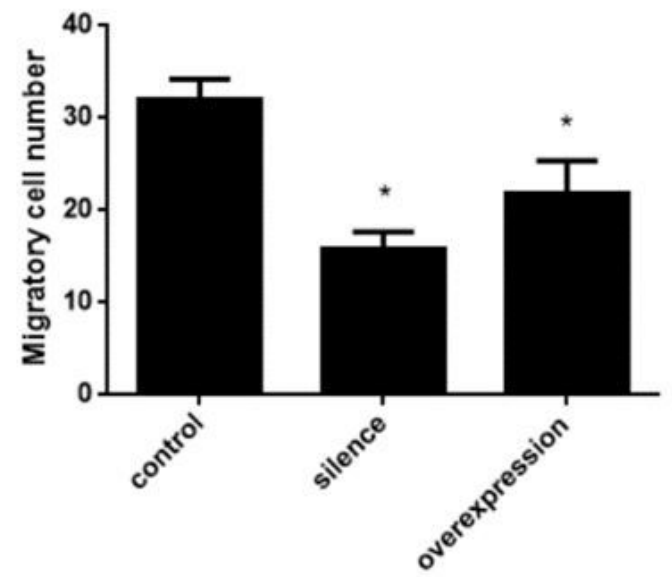

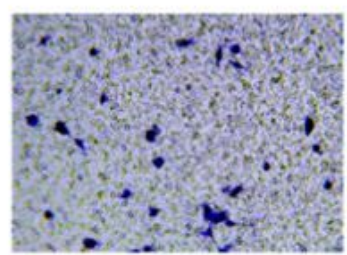

Control

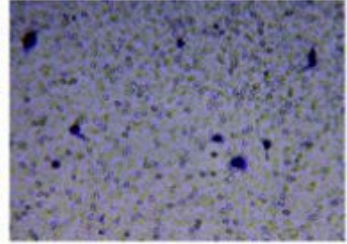

silence

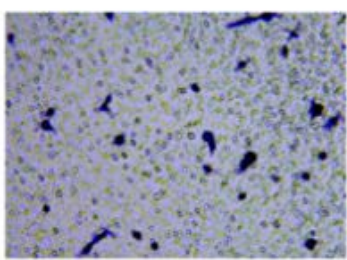

overexpression

\section{Figure 6}

The cell invasion of LncGAPLINC-Knockdown cell line, LncGAPLINC-Overexpression cell line $\left({ }^{\star} p<0.05\right)$.
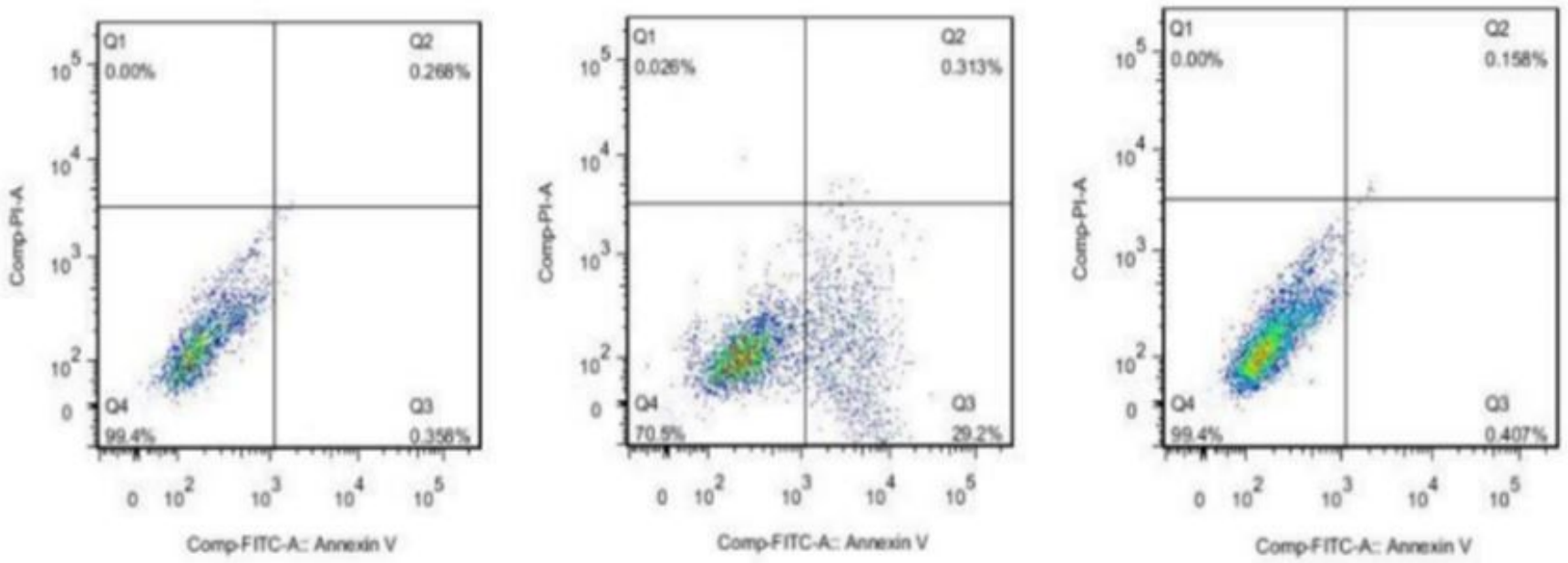

Figure 7

The cell apoptosis of LncGAPLINC-Knockdown cell line, LncGAPLINC-Overexpression cell line. 

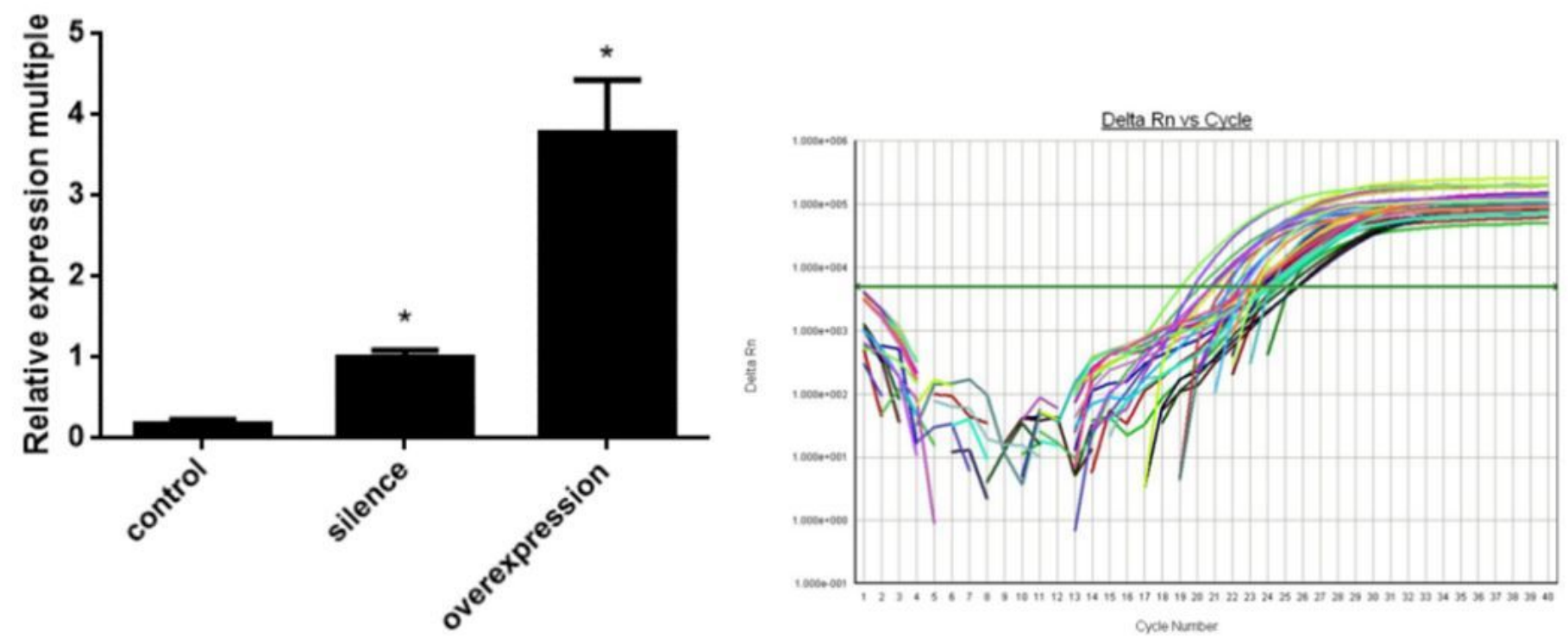

Figure 8

The RNA level of LncRNA GAPLINC. 